\title{
Changing of the Old Guard: Time Travel and Literary Technique in the Work of Kurt Vonnegut
}

\author{
DANIEL CORDLE \\ Nollinghan Trent University
}

[She joined] hands with other old-fashioned storytellers to make people believe that life had leading characters, minor characters, significant details, insignificant details, that it had lessons to be learned, tests to be passed, and a beginning, middle, and an end. '

In a sharp double renunciation, the narrator, in this passage from Breakfast of Champions, neatly draws together two commonplace assumptions: that life is meaningful, and that stories are meaningful. Significantly, in rejecting the idea that life is like a story the narrator, who by implication is very close to Vonnegut himself (later in the novel he appears as Kurt Vonnegut), also rejects the idea that teleological development - $\mathrm{a}$ beginning, a middle, and an end - is anything more than an illusion in either stories or life.

The association between narrative development and meaning ('lessons to be learned') is apposite, for the hackneyed demand that stories have a beginning, middle, and an end is surely founded on the assumption that it is in a traditional sequencing of events that meaning resides: beginning must develop into a recognizably distinct middle, and the end must modify and resolve the issues raised in the middle. When beginning, middle, and end are strung together in one story, a causal and teleological development is implied, and the identification of the cause driving events is what gives meaning to the story.

Even where plot development is little more than a sequence of events lacking a coherent linking narrative drive, say in a picaresque tale, meaning might arise from the teleological imposition of meaning upon the tale by the reader: one thinks here, for instance, of Daniel Defoe's prefaces to Roxana and Moll Flanders where the potentially shocking disregard for consequences by the eponymous narrators, is muted by disclaimers that direct the reader, in the words from Roxana, to take 'Instruction and Improvement' from the stories. ${ }^{2}$ In order to do this, the flow of succeeding events needs to be divided up, in the process of reading, so each falls into a beginning (a state of innocence), a middle (much the most interesting, the fall from grace, which

${ }^{1}$ Kurt Vonnegut, Breakfast of Champions (I andon: Cape, 1973), p. 209.

${ }^{2}$ Danief Defoe, Roxane: The Fortunate Mistress (1724; Oxford: Oxford University Press, 1981), p. 1; Daniel Defoe, The Fortunes and Misfortunes of the Famous Moll Flanders (1 722 ; London: Penguin, 1989 ). 
constitutes most of the stories), or an end (the conscquences, or repentance, of the characters' sins). That these carly novels are nearly all middle (the end of Roxana in which the protagonist pays for her misdemeanours with a 'dreadful Course of Calamities' (pp. 329-3o) is all of six lines long, for instance) is hardly the point; we are asked to extract meaning (bad actions are paid for) by sceing a development over time. ${ }^{3}$ The rise in realism over the next hundred and fifty years accentuated this reliance on narrative development.

It is indecd realism and narrative development with which Vonnegut seems to be taking issue, not only in the passage from Breakfast of Champions cited as an epigraph above, but throughout his euvre. 'Realism' is of course used exclusively here as a term to characterize a certain sort of literature, for Vonnegut would surely claim that his works are realistic in terms of fidelity to lived experience (although it is a very different sort of fidelity from that common in the works of the 'old-fashioned' storytellers from whom he distances himself).

One of the foci of this article is the disruption of narrative development in Vonnegut's work and the pertinence of this disruption to the meaning (or indeed lack of meaning) he ascribes to humanity. The place of people in the world is tied up with their place in history, and Vonnegut is acutcly aware of this. 'This is particularly interesting given the way the year 2000 has become such a focus in popular imagination and the cause of so many contradictory impulses, ranging from the apocalyptic (the millennium bug, the film Strange Days) to the futuristic (films and television series such as 200 I: A Space Odyssey and Space 1999). A year becomes special merely because, unusually, all four constituent figures change together, and this arbitrary notation of time, not even shared universally, has a demonstrable effect (in terms of cultural products) on our sense of who we are, oscillating between a sense of ending (the close of the century and, indeed, of a thousand-year period) and a sense of beginning (a new start, a chance to move on).

Another focus for the article is Stephen Jay Gould's Wonderful Iife, and an entirely different mode of discourse, popular science writing. ${ }^{+}$Gould's discussion of evolution in these books chimes with the argument $\mathbf{I}$ shall make in relation to Vonnegut, because he argues that a misapprehension of evolution and a mistaken emphasis upon progress have led us to misunderstand our place in the world (seeing ourselves as the goal toward which all previous evolutionary traits tended, rather than one more unlikely and fortunate consequence of a series of contingent factors).

The scientific status of Gould's work is of course an entirely inappropriate subject for a literary critic to broach, and it is not the place of this article to

\footnotetext{
"Of course, Defoe may not wish his stories to be read in such a way, but it is interesting that in order to mute: the potential controversy that could be caused by his determined and free female protagonists, he uses the preface to suggest a threc-part tharrative development.

${ }^{4}$ Wondefful life: 7 he Btiggess Shale and the Yature of History (1989; repr. London: Hutchinson, 1990).
} 
suggest whether or not Gould's view constitutes the 'correct' scientific interpretation of evolution. ${ }^{5}$ However, the almost entirely complementary presentations of change over time that we find in Gould's and Vonnegut's work provide an opportunity to do more than merely point out a happy and interesting coincidence. These different discourses, fiction and popular science, are brought together because by addressing the form in which time and narratives coincide they raise identical questions about the meaning of human life. It is hoped that the sort of analysis undertaken here will demonstrate the ways in which the reading of popular scicntific texts is itself essentially similar to the reading of literary texts, and will thus constitute an argument for an appreciation of science writing as a genre of cquivalent literary status to those already recognized.

Vonnegut approaches evolution directly in his novel Galapagos, which follows the fate of the last surviving humans and their ancestors after the rest of the species is wiped out in a plague. Tracing the story a million years into the future, the book charts the evolution of humans into seal-like creatures, living on fish and lacking the big brains we see as essential to humanity. That this version of evolution accords with that described by Gould is backed up by his comment that 'I would (and do) assign it to students in science courses as a guide to understanding the meaning of contingency [in evolution]' (p. 286). Vonnegut is, of course, seeking to do much more than explain the theory of cvolution, but his use of the topic makes this a particularly pertinent choice of novel to place alongside Gould's accounts. However, reference will also be made to other novels by Vonnegut, and one of the central claims of this article is that the view of time apparent in Galapagos is also intrinsic to much of the rest of Vonnegut's fiction and offers at least some explanation for his narrative experimentation.

\section{Novels and novelty: the rejection of teleology}

It has already been noled that Vonnegut seems to distance his work from traditional narrative forms. This is a question of explicit content most obviously in Breakfast of Champions where the setting of an arts festival allows Vonnegut to distance himself from characters such as Beatrice Keedsler, the subject of the epigraph, who arc 'old-fashioned' storytellers.

An alternative model of fiction is provided by the time-travelling aliens, the Tralfamadorians in Slaughterhouse-Fine, who describe their books to Billy Pilgrim in this way: "There is no beginning, no middle, no end, no suspense, no moral, no causes, no effects. What we love in our books are the depths of

"A particularly interesting critique of Gould's view of evolution is made by Richard Dawkins in Chapter 9, of 7 he Blind Wathmaker (Harlow: Longtnan, 1986 ). Dawkins's objection is not so much that Gould is wrong, but that his vicw of cvolution, often terned 'punctuated equilibriurr', is presented as being more imuvat tive than it really is. 
many marvelous moments seen all at one time. ${ }^{16}$ It is very tempting to read this as a template for many of Vonnegut's novels, composed as so many of them are of short staccato sections of prose, separated by numerous white line breaks. 'I'his template scems particularly appealing in relation to Slaughterhouse-Five itself, which, so as to mirror the central character's timetravelling, mixes up the chronology of the tale. Indeed, the title page of the novel even says that it is 'somewhat in the telegraphic schizophrenic manner of tales of the planet 'Tralfamadore'. However, it is only 'somewhat' like Tralfamadorian novels, and it is important to realize that, despite Billy's infatuation with 'Tralfamadorian philosophy, there is an inherently disturbing aspect to their world view from which the novel distances itself, and it would therefore be wrong to suggest that Vonnegut's novel form tries to emulate that described by his imaginary aliens. ${ }^{7}$ Indeed, despite the disruption of chronology, the ordering of events in Slaughterhouse-Fize is extremely significant, and this is an issue I will return to later.

It is nevertheless reasonable to make the point that Vonnegut attempts to distance his fiction from established narrative forms. Gould's telling of the story of evolution, whilst not seeking the innovative form of Vonnegut's fictions (it would be bizarre to suggest that he adopted a 'telegraphic schizophrenic manner' for his books), certainly shares Vonnegut's desire to move on from a style of tale which had bcen canonical. Moreover, at the heart of this new story of evolution is a rejection of the beginning/middle/ end perspective spurned by Breakfast of Champions.

This is most apparent in a subsection of the first chapter of Wonderful life, "The Ladder and the Cone: Iconographies of Progress" (pp. 27-45). 'This explores the ways in which the story of evolution has traditionally involved a narrative of progress, a teleological account that places humanity as the goal towards which evolutionary trends have tended. This is no minor curiosity for it has, Gould argues, shaped our whole understanding of what lies at the heart of evolution: "The straitjacket of lincar advance goes beyond iconography to the definition of evolution: the word itself becomes a synonym for progress' (p. 32). Particularly enlightening in this respect is Gould's discussion of iconic images of evolution, especially that of the sequence of figures, running left to right across the page, each standing more erect than that preceding it, which is frequently used to illustrate the evolution of human beings. Encapsulated in this familiar image is the idea of goal-orientated progress. It suggests, implicitly, that evolution is driven by long-term goals the move from ape to human is smoothly progressive and it implies that humans are the telos of evolution.

\footnotetext{
${ }^{6}$ Kurt Vonnegul, Staughterhouse-Fite: Or: 7he Children's Cinsade: A Duty-Dance with Death (rg69; repr. London: Vintage, Ig91; p. f..1.

'The problem with the Trallamadorian's philosophy is that their' refusal to accept any role for the individual, arguing that everything is already predetermined, leats to a completc abnegation of personal responsibility, cxcusing, in the novel, excesses of violence and a passive acceptance of the status quo.
} 
As with Vonnegut's mockery of old-fashioned story tellers, we have a strong association here between time and meaning. Just as the importance ascribed to characters' lives is intertwined with the beginning/middle/end narrative progression in Breakfast of Champions, so Gould suggests that an interpretation of evolution as progressive and teleological follows from a desire to give meaning to human lives: 'I don't think that any particular secret, mystery, or inordinate subtlety underlies the reasons for our allegiance to these false iconographies of [progress ... ]. 'l'hey are adopted because they nurture our hopes for a universe of intrinsic meaning defined in our terms' (p. 43). The crucial phrase here is 'defined in our terms', for it suggests that our particular perspective, as humans, shapes the meaning we give to cvolution: it resists a possible implication of cvolutionary theory, that we are not divinely created, and reasserts our importance by making intelligent life - ourselves - the goal of evolution. In other words, it gives meaning to our existence.

Both writers, then, display discomfort at the idea of a simple, progressive chronology, suggesting that it panders to our desire to find meaning in our lives and is a powerful form of self-deception. However, before moving on to discuss the alternative perspective they offer, it should be noted that there is of course an unavoidable sense in which a different sort of narrative progression is called upon by both Gould and Vonnegut. By situating themselves as proponents of a new point of view, thcy place their texts in a revolutionary position and therefore at a moment of narrative development: the move from 'old-fashioned' to Vonnegut's fiction, and the move from 'traditional' evolutionary narratives to Gould's accourt. This 'shift up' a level, from the intrid-textual (what the books are about) to the extra-textual (their position in the disciplinary traditions in which they locate themselves), does not of course short-circuit or invalidate their reworkings of the notion of time. Indeed, as will become apparent, it is not being suggested that all development over time is seen as meaningless by these writers; rather, that they ask us to reconsider the different sorts of meanings that are associated with change over time.

\section{Alternative views of change over time: 'Wonderful Life' and 'Galapagos'}

By rejecting a straightforward sense of progress, as outlined above, both Gould and Vonnegut also, of course, inevitably reject a simplistic form of determinism. However, this does not mean that they embrace the opposite, total randomness. It is Gould who states a third possibility most clearly.

Wonderful Life tells the story of the interpretation and reinterpretation of the fossils in an important fossil locality, the Burgess Shale, discovered by Charles Doolittle Walcott in 1909 . According to Gould, the original analysis of the Burgess Shalc fossils, by Walcott himself, proceeded from the assumption that 'fossils fall into a limited number of large and well-known 
groups, and that life's history generally moves toward increasing complexity and diversity' (p. I I ). In other words, this assumption was that there is a definite progress underpinning the history of life on earth: a small number of specics-groups, early on in evolution, inevitably gives rise to a larger number of more complex forms later on.

The alternative approach to the Shale, which Gould endorses, takes a very different point of view and it relies crucially, not on new evidence (the discovery of more fossils), but on a reinterpretation of existing cvidence. Rather than assume that the fossils represent a large number of organisms bclonging to a few, well-known groups, it suggests that the fossils in fact represent numerous groups, many of which have now become extinct. In other words, cvolution has not been a process of steady diversification accompanied by an increasing complexity of life forms, but has involved the mass extinction of many groups of organisms. Furthermore, Gould suggests, it is not possible 10 say from the available evidence which organisms were best fitted to survive into the future: development over time is not a straightforward process. In other words we cannot just apply a simple rule (things get more complex and diversify) in order to understand what happens.

What holds Gould back from endorsing the direct opposite (complete randomness and the suggestion that there is no meaning to the history of life on earth) is the possibility encapsulated in the term 'contingency. 'l'here are rcasons for what happens, and these are best thought of as 'history':

This third alternative represents no more nor less than the essence of history. Its name is contingency and contingency is a thing unto itself, not the titration of determinism by randomness. Science has beeri slow to admit that different explanatory world of history into its domain. [...] Science has also tended to denigrate history, when forced to a confrontation, by regarding any invocation of contingency as less elcgant or meaningful than explanations based directly on timeless 'laws of nature'. (p. 51)

The implication of this is brought out most dramatically in a thought experiment that Gould proposes, in which we are asked to imagine the history of life on earth as a tape recording. If we rewind the tape to the beginning and let history run again, what will happen? Gould argues that we will not see evolution repeat itself. Instead a whole new natural history will emerge: 'a replay of life's tape would yield a substantially different set of surviving anatomies and a later history making perfect sense in its own terms but markedly different from the one we know' (p. 304 ). ${ }^{8}$

'This sort of contingency is also apparent in the view of evolution that emerges in Galapagos. Like Gould, Vonnegut emphasizes periods of predictable change punctuated by moments of uphcaval when contingent factors

' The current patterning of life is determined, in Gould's view, by perinds of mass extinction when survival is cither random or dependent on different rules from those prevailing under normal conditions. For a longer description of the thought experiment described lere, see Gould, Wonderful life, pp. 48-50. 
determine what course evolution will take. Most of Galapagos is set during one of these periods of upheaval when a bacterium that eats human eggs wipes out all except a few surviving humans. The important thing to ask, in order to understand the view of evolution with which Vonnegut presents us, is what determines these humans' survival? Crucially, it is not 'fitness' in any conventional sense, nor do their brains (those conventional markers of human fitness) allow them to use their wits to escape the impending disaster.

Instead, it is a series of accidents. Some have signed up for the 'Nature Cruise of the Century' on the Bahía de Darwin, to the Galápagos islands; others end up on the ship by mistake. None are planning to escape an impending plaguc. One cxample will suffice to demonstrate the emphasis that Vonnegut places on the random factors that bring the survivors into the right place to be lucky enough to escape the deadly bacteria. Six girls of the Kanka-bonos tribe, who are going to be 'mothers of all humankind', rcach Guayaquil, from whence the cruise is due to leave, by an cxtremely tortuous route ${ }^{9}$ Luckily participating in choir practice with a missionary, they avoid being wiped out like the rest of their tribe by an insecticide sprayed from a plane, and are rescued and taken to Guayaquil by a bush pilot. Onice there, the only speaker of their language, Domingo Quezeda, puts them into a life of crime as strect children. When they escape him they happen to be in the right place to take advantage, unknowingly, of a route opened up when a building is broken into by a soldier, Geraldo Delgardo, acting under the influence of paranoid schizophrenic delusions. 'J'his leads them to a bus, carrying other passengers who will prove to be important in evolutionary terms, and who are trying to escape the civil disorder that has enveloped the city. Lven the route eventually taken by the passengers' ship, the Bahia de Darwin, is fortuitous, as it runs aground on the island of Santa Rosalia only because of the captain's ineptitude. People survive, then, because they are lucky; there is nothing about the survivors who get isolated on Santa Rosalia that would have allowed us to predict their 'fitness' to escape the extinction of the rest of the human species.

Once on Santa Rosalia, however, a more orthodox evolutionary pressure begins to assert itself, with the result that, a million years into the luture, humans are small-brained, seal-like, fish-eating creatures:

But in the long run, I don't think it would have made much difference which malcs did the impregnating, Mick Jagger or Dr Henry Kissinger or the Captain or the cabin boy. Humanity would still be pretty much what it is today.

In the long run, the survivors would still have bcen not the most ferocious strugglers but the most efficient fisherfolk. That's how things work in the islands here. (p. 167)

So, as with Gould's account of evolution, there is a rebuttal of a notion of smooth, progressive, predictable development herc, with a crucial cmphasis

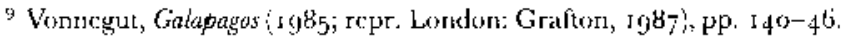


being placed upon periods of crisis when contingent factors can throw cvolutionary development in any one of a number of possible directions. Again, vitally, this reappraisal of humans' place in cvolutionary history is linked to the issue of meaning. By restructuring the evolutionary story so that the arrival of big-brained humans on the planet does not constitute a climactic end, but instead a passing scene in the middle of the narrative, Vonnegut unseats any pretensions we might have to see human existence as intrinsically meaningful.

This is then reinforced throughout the novel by the reiteration, with that wonderful, almost childlike simplicity and bluntness that characterizes Vonnegut's prose, of the failings of human brains. Again and again he repudiates the notion that they are the pinnacle evolutionary achievement: 'Can it be doubted that three-kilogramme brains were once nearly fatal defects in the evolution of the human race?'(p. 16); 'This famine was as purely a product of ovcrsize brains as Bcethoven's Ninth Symphony' (p. 28); 'Mary had also taught that the human brain was the most admirable survival device yet produced by evolution. But now her own big brain was urging her to take the polyethylene garment bag $[\ldots]$ and to wrap it around her head, thus depriving her cells of oxygen' (p. 3o); 'Now there is a big-brain idea I haven't heard much about lately: human slavery' (p. I6i).

So both Gould and Vonnegut, writing within different genres and for different purposes, achieve a comparable displacement of humanity's selfimportance by asking us to reconsider the end of the same basic well-known story of evolution (which almost holds the status of a modern myth). Gould asks us to consider that other possible scenarios could easily be playing themselves out now as the consequence of the minutest difference earlier on ('The divine tape player holds a million scenarios, each perfectly sensible' (p. 320)); Vonnegut asks us to project a million years into the future, and to envision our own fall from superiority.

However, interested as they are in the status of humans' place in the world, both writers offer something to fill the space left by the sense of purpose they have so assiduously shown to be misplaced. Gould leaves us with an existentialist proposition:

The survival of Pikaia [the oldest identifiable ancestor of humans / was a contingency of 'just history.' I do not think that any 'higher' answer can be given, and I cannot imagine that any resolution could be more fascinating. We are the offspring of history, and must establish our own paths in this most diverse and interesting of conceivable universes - onc indifferent to our suffcring, and therefore offering us maximal freedom to thrive, or to fail, in our own chosen way. (p. 323)

Vonnegut also refuses to offer us a greater meaning to our lives than one which we arrive at ourselves. Although he details, not only in Galapagos but in much of his fiction, human failings and the meaninglessness of human cxistence, he also maintains compassion for these flawed creatures. In Galapagos this takes the form of the narrator's feelings about what he 
witnesses over the million-year period of the novel. Having postponcd the opportunity to enter the after-life for so long, and having detailed all the improvements in human existence since the demise of the era of big brains (the removal of self-deception and all those other failings contained in the string of quotations cited above) he decides that he will take the next opportunity to leave the world:

I can expect to sec the bluc tunncl again at any time. I will of course skip into its mouth most gladly. Nothing ever happens around here any more that I haven't seen or heard so many times before. Nubody, surely, is going to write Beethoven's Ninth Symphony -- or tell a lic, or start a Third World War.

Mother was right: even in the darkest times, there really was still hope for human kind. (p. 236)

The final sentence in this quotation is intriguingly ambiguous: where did the hope for human kind lie? Was it with the possibility recorded in the book, that a calamity should befall the human world, and evolutionary pressures would result in the extinction of big brains and all their failings? Or did the hope always lie with the big brains, those fortuitous accidents of evolution, and the possibility that instead of starting a war they would produce music comparable to that of Beethoven?

'This compassion for people, along with all their failings, is apparent in other Vonnegut novels: for instance, in Rosewater's commitment to philanthropy despite the failings of those whom he helps in God Bless You, Mr. Rosewater, and in Salo's final act at the end of The Sirens of Titan, when he hypnotizes the dying Malachi so that he will think that his friend has come. for him. However, importantly, there is rarcly, if ever, a suggestion that anything truly transcends the tragedy of a meaningless existence; the acts of kindness by Rosewater and Salo have significance only on a local level, and do not alter the overall harshness of the worlds with which Vonnegut presents us.

In this sense, Gould's conclusion, quoted above, is significantly more upbeat than that arrived at by Vonnegut. He emphasizes self-determination, establishing 'our own paths', whereas each of Vonnegut's characters is almost always, as Malachi puts it in The Sirens of 7itan, "the victim of a series of accidents." ${ }^{\prime \prime}$ This perspective on the drives that shape human lives, a series of determining accidents, rather than a consistent, meaningful purpose, not only dominates the content of Vonnegut's work but also explains some of the innovative narrative devices apparent in his fiction. The sense that a beginning/middle/end chronology invests the lives of characters with a meaning that is entircly inappropriate is reflected in the forms Vonnegut adopts in order to subvert traditional narrative models. 'Two examples will suffice to illustrate this. 
One motif in Vonnegut's fiction is that of repetition. For instance, characters reappear in different novels, and phrases are repeated throughout novels. This sort of repetition is most famously apparent in Slaughterhouse-Five where the phrase 'so it gocs' appears (by my calculations) so6 times, following immediately after the report of any death, or anything approximating a death, in the text. The mechanical regularity of the appearance of this phrase is a denial of any form of development and progression. This denial is entirely appropriate as 'so it goes' encapsulates the philosophy the Tralfamadorians persuade Billy to accept: everything is predetermined, and individuals are unable to make any difference to the course of events. This belief involves the denial of any meaning to change over time: things just are; each moment is already set before we reach it.

The phrasc encapsulates this in terms of both content (so it goes; that is just how things are) and form (its mechanical appearance denies any meaning to the deaths to which it refers, and refuses to distinguish between people killed in the Dresden firestorm and the death of bubbles in a flat glass of champagne). Of course, although Vonnegut may be trying to distance himself from the meanings ascribed to people's lives in the work of the 'traditional' storytellers he derides in the cpigraph to this article, it does not mean that he is asking us to accept a 'so it goes' philosophy. Indecd, although the chronology of Slaughterhouse-Five is mixed up as we follow Billy on his uncontrolled time-travelling experiences, it is not without any meaning whatsocver. Most importantly, Vonnegut leaves Billy at a moment of choicc. Despite the passivity with which he is characterized throughout the novel, he is left with an opportunity at the end to do something to transgress the pattern of the rest of his life, refuting the Tralfamadorians' beliefs. Although he can do nothing about the grand events that dominate his life (World War Two, the bombing of Dresden, his kidnapping by aliens) we know at the end of the book (becausc the episode is described earlier) that Billy is about to ride a wagon drawn by a poorly shod horse. We also know that his failure to relieve the suffering of the horse will lead him to cry for the only time in his life. This is significant: he cries presumably both bccause the suffering of the horse is on a scale he can appreciate (whereas to grasp the huge scale of the deaths involved in the war is impossible), and because it is something which he could have prevented. By taking us back to the moments just before this episode, Vonncgut again leaves Billy with a moment of choice. The order of events is therefore extremely significant, and although Vonnegut refuses a simple beginning/middlc/end chronology in Slaughterhouse-Five, he is not denying the importance of narrative development. It is in this sense that his novel is different from those of the Tralfamadorians described above. Slaughterhouse-Five is not made of "many marvelious moments seen at one time' like 'Tralfamadorian books, and it is essential that it is not read as such because the order in which the rcader perceives the events of SlaughterhouseFive is significant. 
So the use of repetition, particularly of the cold response to death in phrase 'so it goes', is placed alongside subtle variation in Slaughterhouse-s This tension between repetition and variation produces a significa. different meaning to the "natural" bcginning/middle/end structure of stor What Vonnegut effectively does, therefore, is defamiliarize us from a forr narrative development which has become naturalized in realist pr allowing us to see it, and the meanings produced by it, afresh.

$\Lambda$ similar defamiliarizing effect in relation to narrative developmet achieved with the placing of an asterisk next to the name of characters . arc about to dic in Galapagos. This defuses suspense, short-circuiting reader's expectations of narratives. Although the reader is doubly aware ' the events of the narrative are fixed in advance (doubly aware beca Vonnegut has already writzen the book, and because the narrator is tel the story in retrospect), any sort of suspense or any expectation 1 characters can act to affect the course of events is removed by this dev When an asterisk appears next to the name of a character we know that $\mathrm{s}$ is about to die, regardless of their actions. $\Lambda$ s with 'so it goes' in Slaughterho Five, there is a strong sense of determinism and repetition here. Ag Vonnegut seems to be playing with the notion that human life is $b$ determined and meaningless: events are fixed in advance, but there is meaning or direction to the changes that take place over time.

Because he is investigating this possibility, it is entircly ajppropriate tha should shun a traditional narrative form that invests human lives wit significance they do not have. Both he and Gould suggest that, rather $t$ moving towards an 'cnd', human lives just move. An end implies resolution, whether comic or tragic, of the issues raised by a story. It is closure that Vonnegut's defiance of traditional narrative forms and Gor rejection of a popular version of the story of evolution resist. Both wri though working in very different genres and for dillerent reasons, are un by their perception that time, and change over timc, arc meaningful, also poientially deceptive. They are acutely aware of how meanings constructed by the temporal perspective from which events are seen, this is an insight which is instructive whether we use the narratives of fic or of science to help make sense of our lives. 